\title{
Strong spectral dependence of light absorption by organic carbon particles formed by propane combustion
}

\author{
M. Schnaiter ${ }^{1}$, M. Gimmler ${ }^{1}$, I. Llamas ${ }^{2}$, C. Linke ${ }^{1}$, C. Jäger ${ }^{2}$, and H. Mutschke ${ }^{2}$ \\ ${ }^{1}$ Institute of Meteorology and Climate Research, Forschungszentrum Karlsruhe, Germany \\ ${ }^{2}$ Astrophysical Institute and University Observatory, University of Jena, Germany \\ Received: 13 December 2005 - Published in Atmos. Chem. Phys. Discuss.: 14 March 2006 \\ Revised: 1 June 2006 - Accepted: 30 June 2006 - Published: 18 July 2006
}

\begin{abstract}
We have measured the extinction and absorption cross sections of carbon particles emitted by a propane diffusion flame both in an aerosol chamber and on size-segregated samples deposited on optical windows. The absorption cross section, the single scattering albedo, and the Ångström exponent show drastic dependencies both on the $\mathrm{C} / \mathrm{O}$ ratio and on the particle size. This is interpretated as being due to the appearance of nucleation modes of smaller organic particles at higher $\mathrm{C} / \mathrm{O}$ ratios, which were detected by SMPS measurements and partially by TEM analysis. The spectral range of the validity of the absorption power-law (Ångström exponent) model is investigated by vacuum ultraviolet extinction measurements. These measurements give also indications for a preferentially aromatic nature of the $\mathrm{OC}$ component of the flame products.
\end{abstract}

\section{Introduction}

Soot aerosol emitted by combustion processes, like fossilfuel and biomass burning, directly affects the radiative balance of the earth's atmosphere by scattering and absorption of short-wave solar radiation. In climate research, combustion aerosols are usually classified in two major components, namely black carbon (BC) and organic carbon (OC), which refer to the absorbing and non-absorbing carbon fractions of the aerosol. While this classification is based on the optical properties of the carbonaceous material, most classifications in source characterisation studies rely on the thermal behaviour of the emitted combustion aerosol. Here, OC and elemental carbon (EC) refer to the carbon fractions that thermally desorb in oxygen-free and oxygen-containing atmospheres. EC measurements are often treated as equal to $\mathrm{BC}$ ignoring the possibility that also OC, according to the des-

Correspondence to: M. Schnaiter

(martin.schnaiter@imk.fzk.de) orption definition, may have a significant absorption (Bond et al., 2004).

It is well known that $\mathrm{BC}$ aerosol is the most efficient absorbing aerosol in the atmosphere with a mass-specific absorption cross section $\left(\sigma_{\mathrm{abs}}\right)$ in the visible spectral region of about 7.5 $( \pm 1.2) \mathrm{m}^{2} / \mathrm{g}$ (Bond and Bergstrom, 2006). In several laboratory and field studies it was found that BC aerosol emitted from high-temperature combustion processes has a low $\sigma_{\text {abs }}$ spectral dependence of about $\sim \lambda^{-1}$ (Schnaiter et al., 2003; Kirchstetter et al., 2004). The mass specific and spectral absorption properties of OC aerosol are less well known. However, there is evidence that $\sigma_{\mathrm{abs}}$ of low-temperature combustion aerosol, e.g. from biomass burning, is lower and exhibits a much stronger spectral dependence than aerosol from high-temperature combustion processes, such as diesel soot (Kirchstetter et al., 2004). Usually, $\sigma_{\mathrm{abs}}$, or more precisely the absorption coefficient $b_{\mathrm{abs}}$, is measured by filter-based techniques like the Particulate Soot Absorption Photometer (PSAP) or the Aethalometer, which have systematic filterinduced errors (Bond et al., 1999; Weingartner et al., 2003). Due to these systematic errors $b_{\text {abs }}$ values measured by such filter-based methods are generally enhanced compared to the values measured for airborne particles and, therefore, have to be corrected based on a simultaneous measurement of the aerosol scattering coefficient $b_{\text {sca }}$.

There exist two methods for measuring $b_{\mathrm{abs}}$ on airborne particles, namely the Photoacoustic Spectrometry (PAS) and the difference method (DM). While PAS measures $b_{\text {abs }}$ directly, DM relies on a simultaneous measurement of the aerosol extinction and total scattering coefficients $b_{\text {ext }}$ and $b_{\text {sca. }}$. Since both methods are not as sensitive as the filterbased methods they are usually applied in laboratory investigations or in environments with high aerosol concentrations like in biomass burning plumes. Current PAS instruments operate at single wavelengths, while the DM has been successfully applied to deduce multiwavelength $b_{\text {abs }}$ values of soot containing aerosols (Schnaiter et al., 2003). This

Published by Copernicus GmbH on behalf of the European Geosciences Union. 


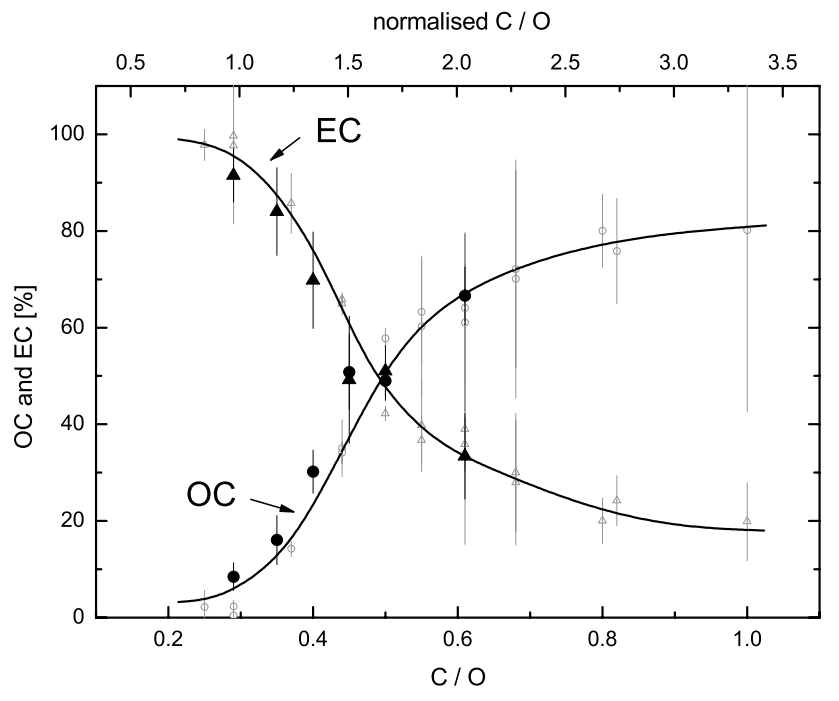

Fig. 1. Dependence of the particle composition (OC and EC content) on the $\mathrm{C} / \mathrm{O}$ atomic ratio in the burner. Full symbols indicate measurements on samples from the NAUA chamber, open symbols indicate samples taken directly behind the CAST burner. The upper scale gives the $\mathrm{C} / \mathrm{O}$ ratio normalised to the stoichiometric ratio of 0.3. The stoichometric ratio separates fuel-lean (normalised $\mathrm{C} / \mathrm{O}$ ratio $<1.0$ ) and fuel-rich (normalised $\mathrm{C} / \mathrm{O}$ ratio $>1$ ) burner conditions.

was achieved by combining a three-colour integrating nephelometer (TSI, mod. 3563) with the aerosol extinction spectrometer LOPES measuring $b_{\text {ext }}$ wavelength-resolved from $200 \mathrm{~nm}$ to $1000 \mathrm{~nm}$ (Schnaiter et al., 2005).

In the present study the DM described by Schnaiter et al. (2005) was utilised to deduce spectral absorption properties of combustion aerosol emitted from a propane diffusion flame operated at different combustion conditions, i.e. at different $\mathrm{C} / \mathrm{O}$ ratios. Additional spectroscopic measurements were performed on size-segregated samples deposited on $\mathrm{CaF}_{2}$ substrates to investigate in particular the spectral absorption properties of the OC aerosol fraction. This approach allows one to also measure the absorption cross section over a larger wavelength range, which gives some insight into the physical reasons for the absorption variability and the validity of the Ångström exponent approach.

\section{Combustion aerosol}

Combustion aerosol was generated within a co-flow diffusion flame of propane and air (Combustion Aerosol Standard, CAST, Jing-CAST Technologies). By variation of the propane-to-air ratio (C/O atomic ratio) $\mathrm{CAST}$ allows the generation of carbonaceous aerosols with OC to total carbon (TC) mass ratios which vary over a broad range from a few $\%$ to more than $80 \%$ (Fig. 1). CAST was operated with the following flow parameters: 0.06 SLM propane (fuel), 7.5 SLM

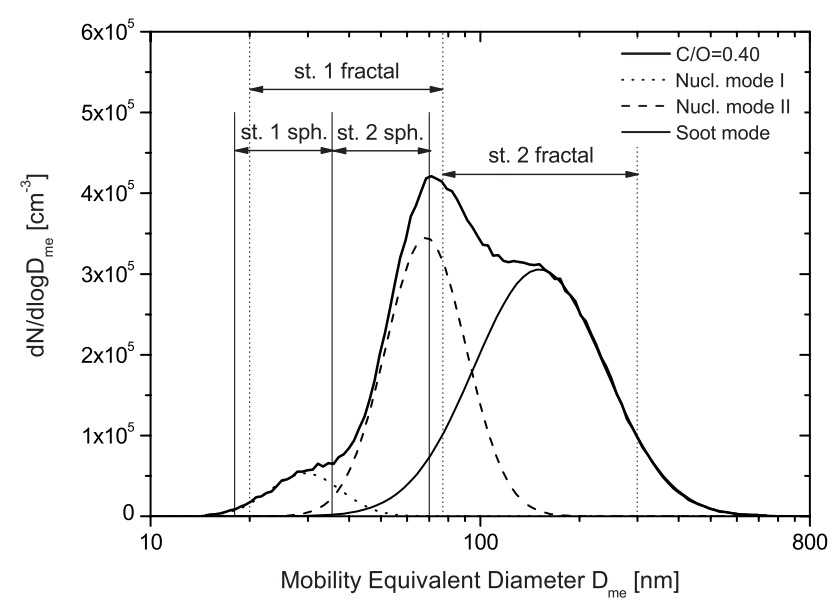

Fig. 2. Number size distribution measured by SMPS for an aerosol produced by the CAST at $\mathrm{C} / \mathrm{O}=0.40$. The vertical lines indicate the size ranges deposited on impactor stages 1 and 2 for the cases of compact spherical particles and fractal aggregates, respectively (see Sect. 4.1 and Sect. 4.2).

nitrogen (quenching gas), 20 SLM synthetic air (dilution after quenching). The co-flow of the oxidation air (synthetic air) was chosen according to the desired $\mathrm{C} / \mathrm{O}$ ratio and thus varied from 0.44 SLM $(\mathrm{C} / \mathrm{O}=0.98)$ to $1.76 \mathrm{SLM}(\mathrm{C} / \mathrm{O}=0.24)$. Note that we use the $\mathrm{C} / \mathrm{O}$ atomic ratio to describe the operation conditions of the burner rather than the fuel-to-air volume ratio. The $\mathrm{C} / \mathrm{O}$ ratio is calculated from the actual fuel-to-air ratio, i.e. the actual flow conditions of the burner by

$\mathrm{C} / \mathrm{O}=7.16 \times \frac{f_{f}}{f_{\text {air }}}$

with $f_{f}$ and $f_{\text {air }}$ the standard volumetric flows of the propane fuel and the oxidation air, respectively.

Prior to the chamber experiments described in the next section, the CAST aerosol emission was characterised in a separate study. For this purpose, the number concentration and size distribution of the combustion aerosol was measured directly behind the CAST output via a 1:100 dilution stage composed of two 1:10 stages (PALAS, VKL 10), to avoid a significant particle coagulation in the instrument lines. Dilution-corrected number concentrations in the range from $1 \times 10^{7} \mathrm{~cm}^{-3}$ to $5 \times 10^{7} \mathrm{~cm}^{-3}$ were measured by a condensation particle counter (CPC, TSI mod. 3022A). Maximum particle emission was found at a $\mathrm{C} / \mathrm{O}$ ratio of about 0.5 . Number size distributions in the $10 \mathrm{~nm}$ to $800 \mathrm{~nm}$ size range were measured by a scanning mobility particle sizer (SMPS) composed of a differential mobility analyser (DMA, TSI mod. 3071) and another CPC (TSI mod. 3010). The mobility equivalent median diameter was found to decrease with increasing $\mathrm{C} / \mathrm{O}$ ratio starting from values between $300 \mathrm{~nm}$ and $340 \mathrm{~nm}$ for the $\mathrm{C} / \mathrm{O}$ ratios 0.25 and 0.29 to less than 


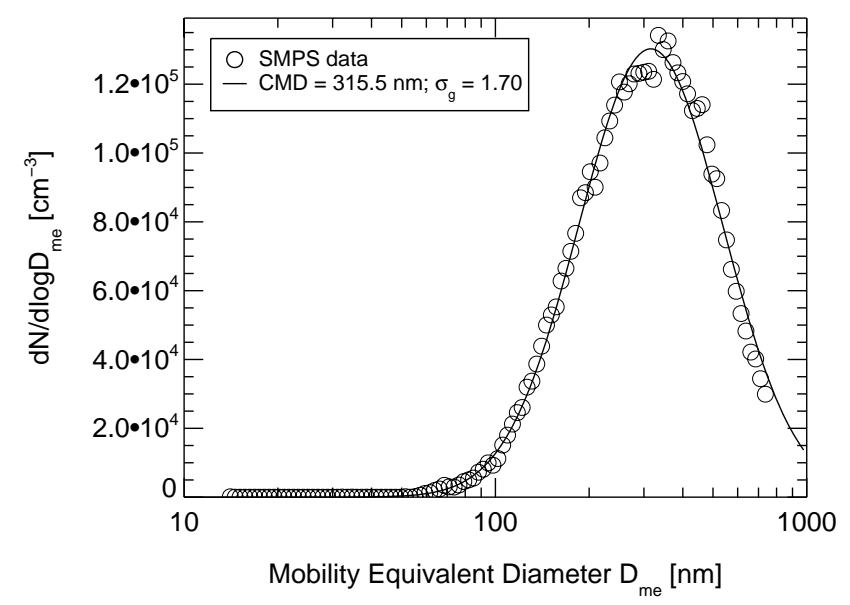

Fig. 3. Number size distribution of CAST aerosol produced at $\mathrm{C} / \mathrm{O}=0.40$ and sampled from the chamber after the initial strong coagulation phase. The measured distribution is well reproduced by assuming lognormally distributed equivalent diameters.

$40 \mathrm{~nm}$ for the highest $\mathrm{C} / \mathrm{O}$ ratio of 1.0 . However, for $\mathrm{C} / \mathrm{O}$ ratios between 0.33 and 0.44 bi- and trimodal size distributions were measured, with one or two nucleation modes in addition to the soot mode (Fig. 2). We assign these nucleation modes to condensed PAH compounds, which are produced in the hotter regions of the flame and which survive the transition to the colder flame regions where they can condense either homogeneously or heterogeneously on the surfaces of the the soot particles. Particles composed of condensed PAH compounds have been detected in flames by several authors using mass spectrometry and transmission electron microscopy (Fletcher et al., 1998; Dobbins et al., 1998; Homann, 1998; Vander Wal, 1998). More recently, Slowik et al. (2004) analysed aerosols generated in a premixed propane $/ \mathrm{O}_{2}$ flame by means of an Aerodyne aerosol mass spectrometer. They found at higher $\mathrm{C} / \mathrm{O}$ ratios of the flame, i.e. at lower flame temperatures, an increasing amount of $\mathrm{PAH}$ compounds in the emitted aerosol. A maximum PAH mass fraction of about $50 \%$ was deduced. Moreover, their further analysis of the aerodynamic aerosol properties indicated a compact particle shape of the condensed PAHs/soot mixtures in contrast to the open-structured soot aggregates. Our TEM analysis of the CAST aerosol (Fig. 4) indeed has revealed two morphologically different particle types: (a) soot aggregates formed from very small individual particles (diameter about $30 \mathrm{~nm}$ ) and (b) spherical particles of up to $120 \mathrm{~nm}$ diameter. In Fig. 4 both types are visible. Some of the large spherical type $b$ particles are indicated by arrows in the micrograph. They are either attached to the soot aggregates or appear individually or in small aggregates. Apparently, they represent the nucleation modes observed in the CAST emission for $\mathrm{C} / \mathrm{O}$ ratios larger than 0.33 , especially the larger nucleation mode II. The nucleation mode I particles should be of about the same size as the individual soot grains. Such a separate mode of small

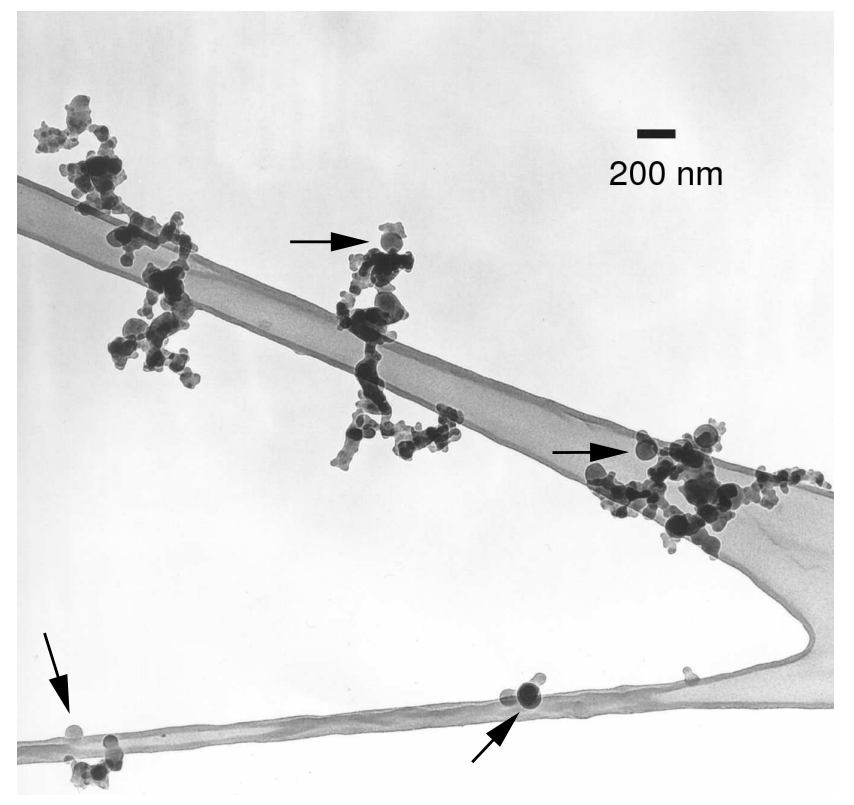

Fig. 4. TEM image showing the morphologies of carbonaceous aerosol particles produced at $\mathrm{C} / \mathrm{O}=0.45$. The arrows indicate larger spherical particles either isolated or attached to the soot aggregates. The long structures to which the particles are attached are bars of the supporting film.

isolated grains, however, has not been seen with the TEM. This can be understood considering that the TEM sample was sampled from the aerosol chamber after the aerosol has been strongly aged by coagulation (see Sect. 3.2).

\section{Aerosol chamber measurements}

\subsection{Methods}

The experiments were conducted at the stainless steel aerosol chamber NAUA of Forschungszentrum Karlsruhe (Fig. 5). The chamber has a volume of $3.7 \mathrm{~m}^{3}$ and is equipped with a comprehensive set of aerosol instruments. Number concentration and size distribution of the aerosol in the chamber were measured by the set of devices mentioned in the previous section. Due to the high initial particle concentrations of $10^{5} \mathrm{~cm}^{-3}$, the sample air of these instruments was diluted 1:10 with synthetic air.

The spectral extinction coefficient $b_{\text {ext }}(\lambda)$ was measured in the spectral range from $\lambda=230 \mathrm{~nm}$ to $\lambda=1015 \mathrm{~nm}$ by the aerosol extinction spectrometer LOPES. LOPES was operated in combination with a three-colour integrating nephelometer (TSI, model 3563) measuring $b_{\text {sca }}(\lambda)$ at $\lambda=450 \mathrm{~nm}$, $550 \mathrm{~nm}$ and $700 \mathrm{~nm}$. By subtracting $b_{\text {sca }}$ from $b_{\text {ext }}$ the absorption coefficient $b_{\mathrm{abs}}(\lambda)$ could be determined at the three nephelometer wavelengths, including a careful correction of the systematic errors of the TSI 3563 nephelometer as already discussed in Schnaiter et al. (2005). However, since 


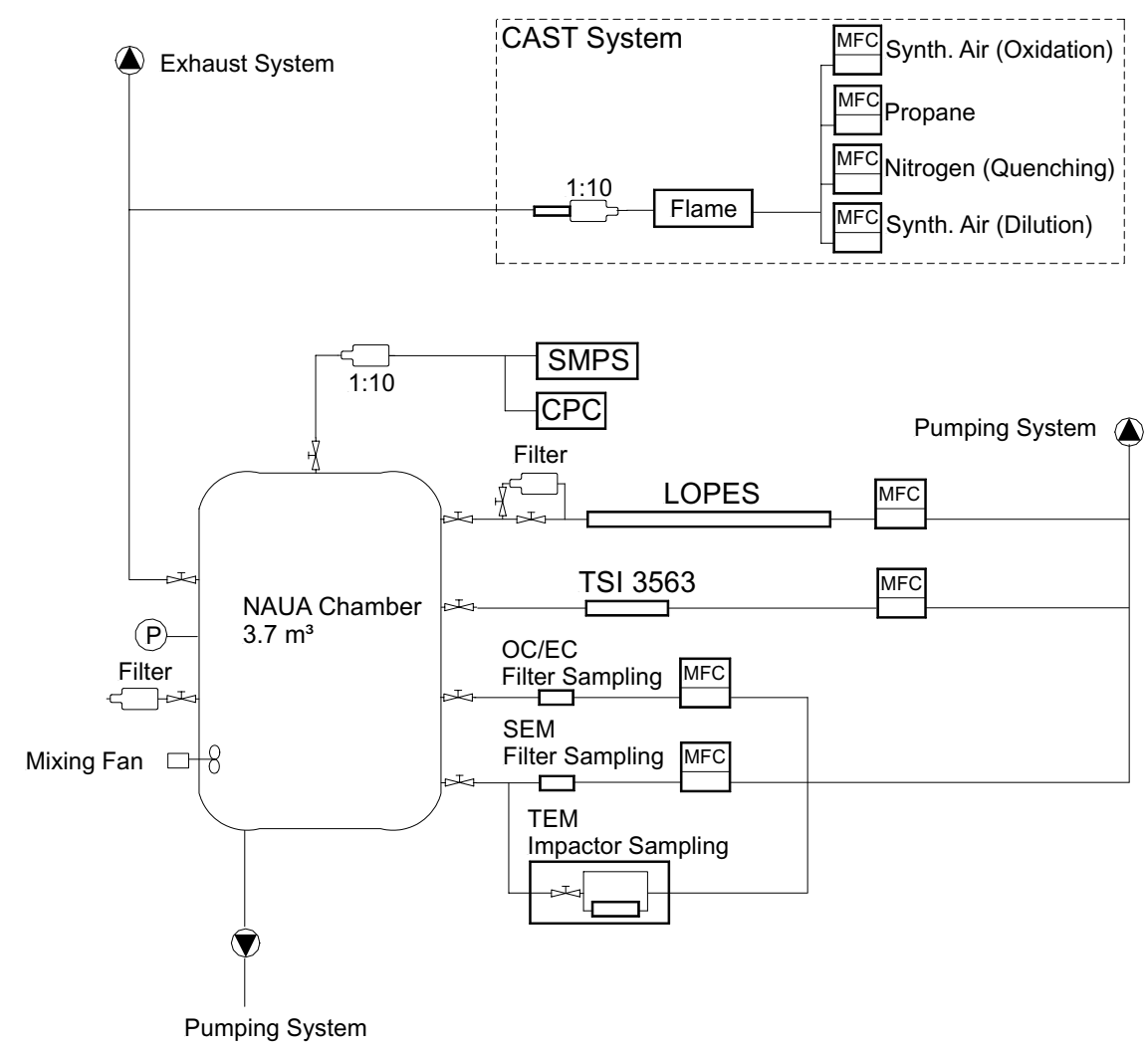

Fig. 5. Schematic representation of the aerosol chamber setup.

we had particle diameters of less than $300 \mathrm{~nm}$ in our experiments the systematic errors of the nephelometer were found to be low (less than 5\%). Thus, the main errors in the presented optical quantities are due to the instrument noise of LOPES $\left(4 \times 10^{-5} \mathrm{~m}^{-1}\right)$ and the accuracy in the determination of the mass concentration.

Quartz filter samples for off-line thermographic carbon analysis were collected directly from the non-diluted output of CAST as well as from the aerosol chamber. Resulting TC mass concentrations of the aerosol in the chamber were used to convert the corresponding $b_{\text {ext }}(\lambda)$ and $b_{\text {abs }}(\lambda)$ results to the mass specific extinction and absorption cross sections $\sigma_{\text {ext }}(\lambda)$ and $\sigma_{\text {abs }}(\lambda)$. Thermographic carbon analysis was accomplished according to the German VDI-guideline 2465, part 2 (VDI, 1999). We used a thermal carbon analyser system developed at the Institute of Environmental Technology of the Technical University of Berlin (Ulrich et al., 1990). Combustion aerosol samples were deposited on quartz fibre filters (Munktell, type MK 360) which have been prefired at $650^{\circ} \mathrm{C}$ for at least $12 \mathrm{~h}$ prior to sampling. According to Ulrich et al. (1990), the filter samples were analysed without any pretreatment by the following three-stage temperature protocol of 8 min duration. In the first stage, low-volatile OC compounds of the aerosol were volatilised in a $350^{\circ} \mathrm{C}$ helium flow (purity grade 5.0), catalytically oxidised, and the carbon frac- tion determined as $\mathrm{CO}_{2}$ by NDIR spectrometry. The carbon fraction was classified as OCI. In the second stage, remaining OC compounds were volatilised at $650^{\circ} \mathrm{C}$ in a helium flow and were classified as OCII. In the last stage, the remaining sample was burned in a $650^{\circ} \mathrm{C}$ oxygen flow (purity grade 4.8). The detected carbon fraction was classified as EC. Before switching from helium flow in stage two to oxygen flow in stage three the sample was cooled down to $300^{\circ} \mathrm{C}$. High heating rates of $12^{\circ} \mathrm{C} \mathrm{s}^{-1}$ were applied to reduce charring of hydrocarbons, in particular during stage two. However, charring of OC cannot completely ruled out which should be keep in mind when comparing our EC/OC ratios with results of other thermal methods. Despite this possible bias, at least the observed trend in the EC/OC ratio with varying burning conditions, i.e. the $\mathrm{C} / \mathrm{O}$ ratio, is reliable. The instrument is routinely calibrated by injecting known doses of $\mathrm{CO}_{2}$ (purity grade 4.5). From these calibrations a precision of better than $7 \%$ can be deduced. A detection limit of about $1 \mu \mathrm{g} \mathrm{EC}$ or OC per sample were determined by analysing a series of blank filters.

Samples for transmission electron microscopy (TEM) were prepared on nickel grids with Lacey carbon support film utilising a self-constructed impactor with a cut-off diameter of $0.1 \mu \mathrm{m}$ by courtesy of M. Ebert, University of Darmstadt, Germany. The grids were analysed utilising a Carl Zeiss 

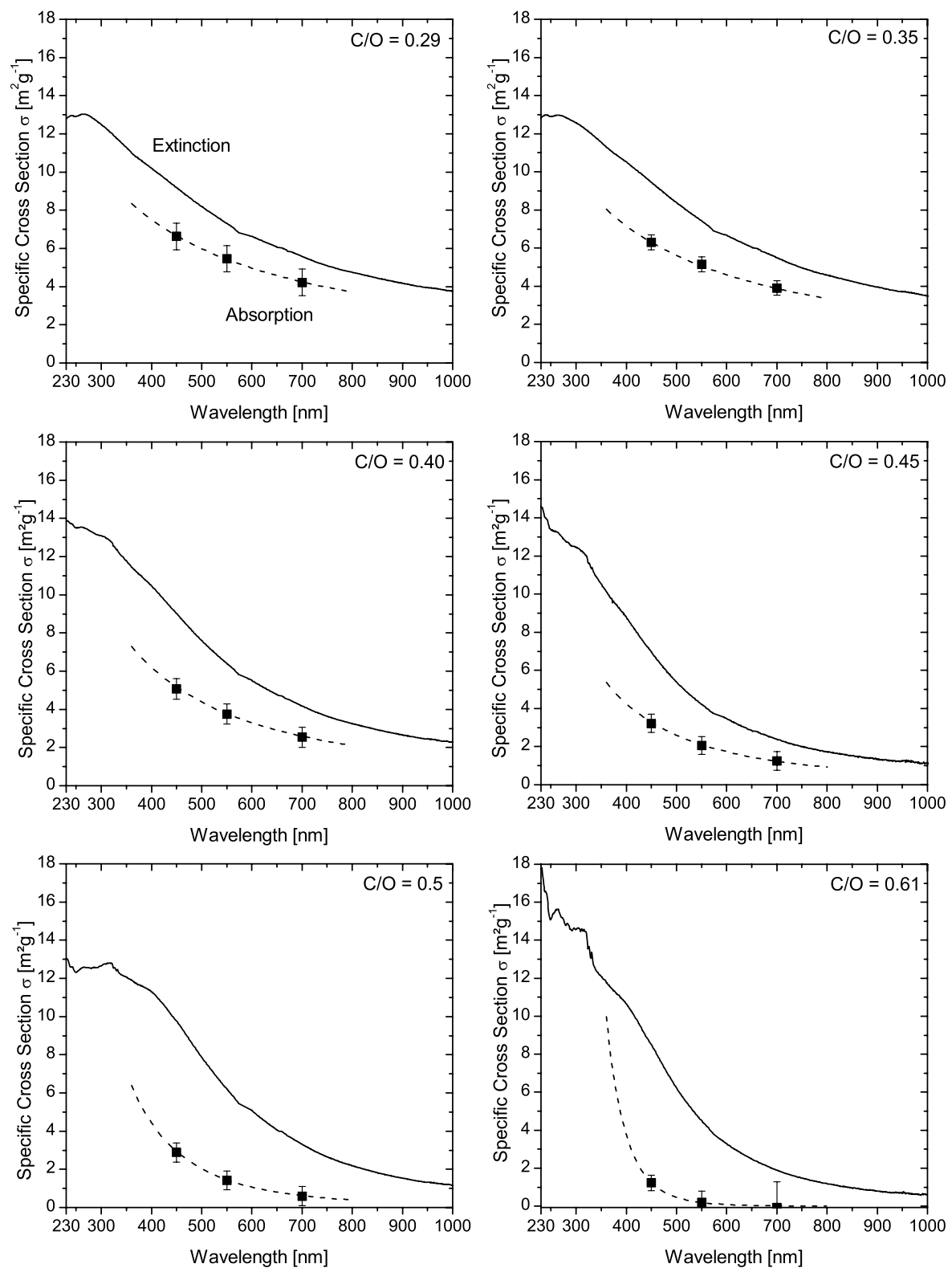

Fig. 6. Specific extinction (solid lines) and absorption (squares) cross sections derived for NAUA aerosol samples produced at different C/O ratios. The absorption values originate from extinction and total scattering (nephelometer) measurements (difference method, see Sect. 1). Dashed lines represent power laws fitted through the measured absorption cross sections.

EM 902 A TEM operating at an accelerating voltage of $80 \mathrm{kV}$ with a point resolution of $1 \mathrm{~nm}$.

\subsection{Procedure}

Before adding the aerosol to the chamber, CAST was operated for at least $20 \mathrm{~min}$ at a $\mathrm{C} / \mathrm{O}$ ratio of 0.29 to achieve stable burning conditions. According to the desired $\mathrm{C} / \mathrm{O}$ ratio, the flow of the oxidation air was then chosen between 0.72 SLM and 1.50 SLM. Experiments were conducted at $\mathrm{C} / \mathrm{O}$ ratios of $0.29,0.35,0.40,0.45,0.5$ and 0.61 . Due to the high car- bon mass emissions of 100 to $200 \mathrm{mg} \mathrm{m}^{-3}$ in case of low $\mathrm{C} / \mathrm{O}$ ratios $(0.29$ to 0.45$)$, the aerosol was diluted with synthetic air in a 1:10 dilution stage before adding it to the chamber. At the higher $\mathrm{C} / \mathrm{O}$ ratios the CAST aerosol was added non-diluted. The chamber was evacuated, flushed, and prefilled with synthetic air before each experiment. Combustion aerosol particles were then added to the chamber by pumping 20 SLM CAST aerosol through the chamber volume where it was mixed with the chamber air by a mixing fan. Depending on the $\mathrm{C} / \mathrm{O}$ ratio the time for enriching the chamber air to a number particle concentration of about $2 \times 10^{5} \mathrm{~cm}^{-3}$ varied 
Table 1. Overview of the optical properties deduced from the aerosol experiments in the NAUA chamber.

\begin{tabular}{cccccccc}
\hline $\mathrm{C} / \mathrm{O}$ & OC/TC $[\%]$ & $\omega_{450}$ & $\omega_{550}$ & $\omega_{700}$ & $\sigma_{\mathrm{abs}}^{550}\left[\mathrm{~m}^{2} / \mathrm{g}\right]$ & $\alpha_{\mathrm{abs}}$ & $\alpha_{\text {sca }}$ \\
\hline 0.29 & $8.5 \pm 2.9$ & $0.27 \pm 0.01$ & $0.25 \pm 0.01$ & $0.22 \pm 0.01$ & $5.5 \pm 0.7$ & $1.01 \pm 0.01$ & $1.70 \pm 0.03$ \\
0.35 & $16.0 \pm 5.0$ & $0.33 \pm 0.01$ & $0.31 \pm 0.01$ & $0.27 \pm 0.01$ & $5.2 \pm 0.4$ & $1.10 \pm 0.02$ & $1.76 \pm 0.03$ \\
0.40 & $30.2 \pm 4.5$ & $0.43 \pm 0.02$ & $0.41 \pm 0.02$ & $0.37 \pm 0.02$ & $3.8 \pm 0.5$ & $1.56 \pm 0.03$ & $2.16 \pm 0.05$ \\
0.45 & $50.8 \pm 7.7$ & $0.53 \pm 0.01$ & $0.51 \pm 0.02$ & $0.46 \pm 0.04$ & $2.1 \pm 0.5$ & $2.20 \pm 0.16$ & $2.84 \pm 0.06$ \\
0.50 & $49.0 \pm 4.1$ & $0.70 \pm 0.02$ & $0.76 \pm 0.02$ & $0.80 \pm 0.02$ & $1.4 \pm 0.5$ & $3.49 \pm 0.12$ & $2.22 \pm 0.11$ \\
0.61 & $66.6 \pm 5.9$ & $0.85 \pm 0.04$ & $0.96 \pm 0.05$ & $1.06 \pm 0.12$ & $0.2 \pm 0.6$ & $9.34^{\mathrm{a}}$ & $2.95 \pm 0.20$ \\
\hline
\end{tabular}

a deduced in the $\lambda=450-550 \mathrm{~nm}$ spectral region

between $20 \mathrm{~min}$ and $2 \mathrm{~h}$. At such high particle concentrations, the aerosol ages very rapidly by coagulation. To avoid a significant coagulation-induced change in the aerosol size distribution during the sampling time of LOPES (10 min), a decrease of the number concentration to at least $7 \times 10^{4} \mathrm{~cm}^{-3}$ was awaited before the optical measurements were started. During the subsequent 2-3 h measurement phase, 4-6 extinction spectra were recorded simultaneously to measurements of the number size distribution. Particle number concentrations and the scattering coefficients were measured continuously. For each experiment, quartz fibre filters for thermographic analysis were prepared simultaneously to the first and last extinction measurement. Nickel grids for TEM analysis were prepared after the first extinction measurement.

\subsection{Results}

Good agreement of the OC/EC composition was found by comparing filter samples collected directly behind CAST and from the NAUA chamber (Fig. 1). However, in contrast to the size distributions measured directly at the diluted CAST output (cf. Fig. 2), the chamber aerosol at any C/O ratio exhibited a mono-modal size distribution, which is a result of the strong coagulation during the aerosol addition and initial ageing phase (Fig. 3).

Results of measured and deduced spectral optical properties are given in Fig. 6 and Table 1. Thus, a clear dependence of the spectral optical properties on the burner gas composition is observed. With increasing $\mathrm{C} / \mathrm{O}$ ratio, i.e. with increasing OC content, light scattering by the aerosol becomes more and more pronounced and eventually dominates the aerosol optical behaviour for $\mathrm{C} / \mathrm{O}$ ratios above 0.45 . This is reflected by the strong increase of the single scattering albedo $\omega_{0}(\lambda)$, i.e. the ratio of scattering to extinction, starting at an absorption dominated value of $\omega_{0}(550 \mathrm{~nm})=0.25$ for the $\mathrm{C} / \mathrm{O}=0.29$ aerosol to a scattering dominated value of 0.96 for the $\mathrm{C} / \mathrm{O}=0.61$ aerosol. Note that the gradient of the spectral dependence of $\omega_{0}$ is turning from negative to positive with increasing OC. Note also that the unphysical mean $\omega_{0}(700 \mathrm{~nm})$ value of 1.06 deduced for the $\mathrm{C} / \mathrm{O}=0.61$ experiments is the result of an increasing experimental error of the DM for slightly absorbing aerosols.

The specific cross sections $\sigma_{\text {ext }}(\lambda)$ and $\sigma_{\text {abs }}(\lambda)$ both decrease with increasing OC content. In particular the absorption cross section $\sigma_{\mathrm{abs}}(\lambda)$ is strongly reduced starting from a value of $\sigma_{\mathrm{abs}}(550)=5.5 \pm 0.7 \mathrm{~m}^{2} \mathrm{~g}^{-1}$ for $\mathrm{C} / \mathrm{O}=0.29$ aerosol to a value of $\sigma_{\text {abs }}(550)=0.2 \pm 0.6 \mathrm{~m}^{2} \mathrm{~g}^{-1}$ in case of the aerosol emitted from a flame with a $\mathrm{C} / \mathrm{O}$ ratio of 0.61 . The relative strength of this decrease is wavelengthdependent and is higher for longer wavelengths resulting in a steeper wavelength-dependence of $\sigma_{\mathrm{abs}}(\lambda) \sim \lambda^{-\alpha_{\mathrm{abs}}}$ and, thus, a higher absorption Ångström exponent $\alpha_{\mathrm{abs}}$ for aerosols with higher OC content. A flat $\lambda^{-1}$ dependence was found for the aerosol samples with OC contents below $20 \%$ in good agreement with what is usually adopted for BC (see Kirchstetter et al., 2004, and references therein). On the other hand, strong wavelength-dependencies of $\sigma_{\mathrm{abs}}$ with $\alpha_{\mathrm{abs}}$ exponents between 2.2 and 3.5 were deduced for the aerosol samples with OC/TC contents around 50\%. Comparable strong spectral dependencies have been found by Bond (2001) for some aerosol samples emitted in coal combustion and by Kirchstetter et al. (2004) and Schnaiter et al. (2005) for biomass burning aerosols. In accordance with the interpretation of the nucleation modes observed in the CAST aerosol in case of higher $\mathrm{C} / \mathrm{O}$ ratios (Sect. 2) we assign the observed correlation of the absorption Ångström exponent with the $\mathrm{C} / \mathrm{O}$ ratio, i.e. the $\mathrm{OC}$ content, to the occurrence of condensed organic species (most likely PAHs) having a steep absorption edge towards the near-UV (Apicella et al., 2004). This interpretation was further supported by spectroscopic investigations of size-segregated impactor samples deposited on $\mathrm{CaF}_{2}$ substrates. These investigations will be discussed in the following section. 


\section{Measurements on impactor-deposited samples}

\subsection{Methods}

CAST aerosol emitted at $\mathrm{C} / \mathrm{O}$ ratios of $0.29,0.40$ and 0.50 were deposited on $\mathrm{CaF}_{2}$ substrates, i.e. optical plates of $25 \mathrm{~mm}$ diameter, utilising an impactor with rotating stages (Hauke, model LPI ROT 25/0.018/2.0). The impactor was operated directly behind the 1:10 diluted output of CAST. Samples were prepared on the first and the second stage of the impactor with cut-off diameters of $0.018 \mu \mathrm{m}$ and $0.0355 \mu \mathrm{m}$. The deposited mass was typically $1 \times 10^{-6} \mathrm{~g} \mathrm{~cm}^{-2}$ at stage one and $2 \times 10^{-6} \mathrm{~g} \mathrm{~cm}^{-2}$ at stage two.

The extinction, absorption and scattering spectra of the samples deposited on the $\mathrm{CaF}_{2}$ substrates have been measured with a double-beam scanning UV-VIS spectrometer (Perkin Elmer, model Lambda 19) in the wavelength range from $190 \mathrm{~nm}$ to $2000 \mathrm{~nm}$. The spot of the spectrometer beam is approximately $4 \times 2 \mathrm{~mm}^{2}$ in size and the spectral resolution was set to $1 \mathrm{~nm}$. Additionally, a VUV spectrometer (special design by LZ Hannover) has been used to extend the extinction measurements to shorter wavelengths (spectral range $115 \mathrm{~nm}-230 \mathrm{~nm}$ ) at a similar spectral resolution and similar beam size. To deduce mass-specific extinction cross sections $\sigma_{\text {ext }}$ of the deposited aerosol, a simple transmission measurement at a sample-covered position on the $\mathrm{CaF}_{2}$ substrate was performed relative to a transmission measurement at a blank substrate position. The relative transmission $T_{\text {rel }}$ is transformed to $\sigma_{\text {ext }}$ by

$\sigma_{\mathrm{ext}}=-\ln \left(T_{\mathrm{rel}}\right) / \mu_{T C}$

where $\mu_{T C}$ is the deposited sample mass per area. For unknown reasons, some data have been found to suffer from insufficient compensation of absorption bands of the $\mathrm{CaF}_{2}$ substrates at wavelengths smaller than about $160 \mathrm{~nm}$. Therefore, we omitted any $\sigma_{\text {ext }}$ values in this shorter wavelength range. The discussion in the following section is not affected by this restriction.

For the determination of the absorption and scattering cross sections, an integrating-sphere accessory for the Lambda 19 spectrometer, equipped with a photo-multiplier detector, was utilised. The sample was placed in the center of the diffusely reflecting integrating sphere of $15 \mathrm{~cm}$ diameter. A tilt of the sample by $15 \mathrm{deg}$ with respect to the beam direction ensures that light reflected by the $\mathrm{CaF}_{2}$ substrate could either leave the sphere through a special port or be retained within the sphere when closing the port. A similar port for the transmitted light could also be either opened or closed. In this way the integrating sphere can be operated in two modes. For scattering measurements, both ports are opened and the intensity of the scattered radiation $I_{\text {sca }}$ collected by the sphere is measured. For absorption measurements, both ports are closed and the sum of reflected, scattered, and transmitted intensities $I_{\text {refl }+ \text { sca+tra }}$ is measured. The measure-
Table 2. Overview of the optical properties deduced from the impactor samples.

\begin{tabular}{ccccccc}
\hline $\mathrm{C} / \mathrm{O}$ & OC/TC [\%] & $\omega_{450}$ & $\omega_{550}$ & $\omega_{700}$ & $\sigma_{\mathrm{abs}}^{550}\left[\mathrm{~m}^{2} / \mathrm{g}\right]$ & $\alpha_{\mathrm{abs}}$ \\
\hline \multicolumn{7}{c}{ First stage } \\
0.29 & - & 0.236 & 0.233 & 0.226 & 6.6 & 1.05 \\
0.40 & 63.6 & 0.405 & 0.407 & 0.395 & 3.5 & 1.76 \\
0.50 & 64.1 & 0.435 & 0.565 & 0.782 & 0.81 & 6.99 \\
0.29 & - & 0.203 & 0.207 & 0.212 & 6.6 & 0.84 \\
0.40 & 52.6 & 0.421 & 0.453 & 0.516 & 4.7 & 1.57 \\
0.50 & 64.9 & 0.526 & 0.648 & 0.778 & 1.9 & 3.32 \\
\hline
\end{tabular}

ment of the incident intensity $I_{\text {inc }}$ at removed sample and closed ports completes the measurements with the integrating sphere. With this set of measurements, the scattered and absorbed fractions relative to the incident intensity can be expressed by $S=I_{\text {sca }} / I_{\text {inc }}$ and $A=1-I_{\text {refl }+ \text { sca }+ \text { tra }} / I_{\text {inc }}$. The value $1-A-S$ should coincide with $T_{\text {rel }}$ from the extinction measurement. This has been checked and is always the case to within a deviation of $(1-A-S)-T_{\text {rel }}<0.05$, in most cases much better. Thus, the absorption, scattering, and extinction cross sections were internally consistent, except for a few cases in spectral ranges of very low extinction, where the deviation became comparable to or even larger than the extinction value itself. Apart from this internal consistency, however, there are systematic deviations from the aerosol measurements in extinction and scattering. This is due to the fact that both the scattering and extinction measurements suffer from insensitivity to forward scattering because of (1) forward scattered light is not detected in the scattering measurement if the scattering angle is small enough so that it passes through the transmission port $(2 \mathrm{~cm}$ in diameter) of the integrating sphere and (2) forward scattered light reaches the spectrometer detector in the transmission measurement if the scattering angle is small enough to match the divergence of the spectrometer beam geometry, i.e. the acceptance angle of the spectrometer detector. Fortunately, the angular limits within which this is the case are similar (about $\pm 7 \mathrm{deg}$ ) in both measurement modes so that the effects are partially compensated and the above-mentioned consistency is maintained. However, depending on the relative strength of forward scattering, the scattering cross section can be considerably underestimated. This effect should become increasingly important at shorter wavelengths and is in fact seen as a reduction of the albedo, especially for the samples produced at high $\mathrm{C} / \mathrm{O}$ (see Table 2). The absorption measurement is not affected by such systematic errors. 

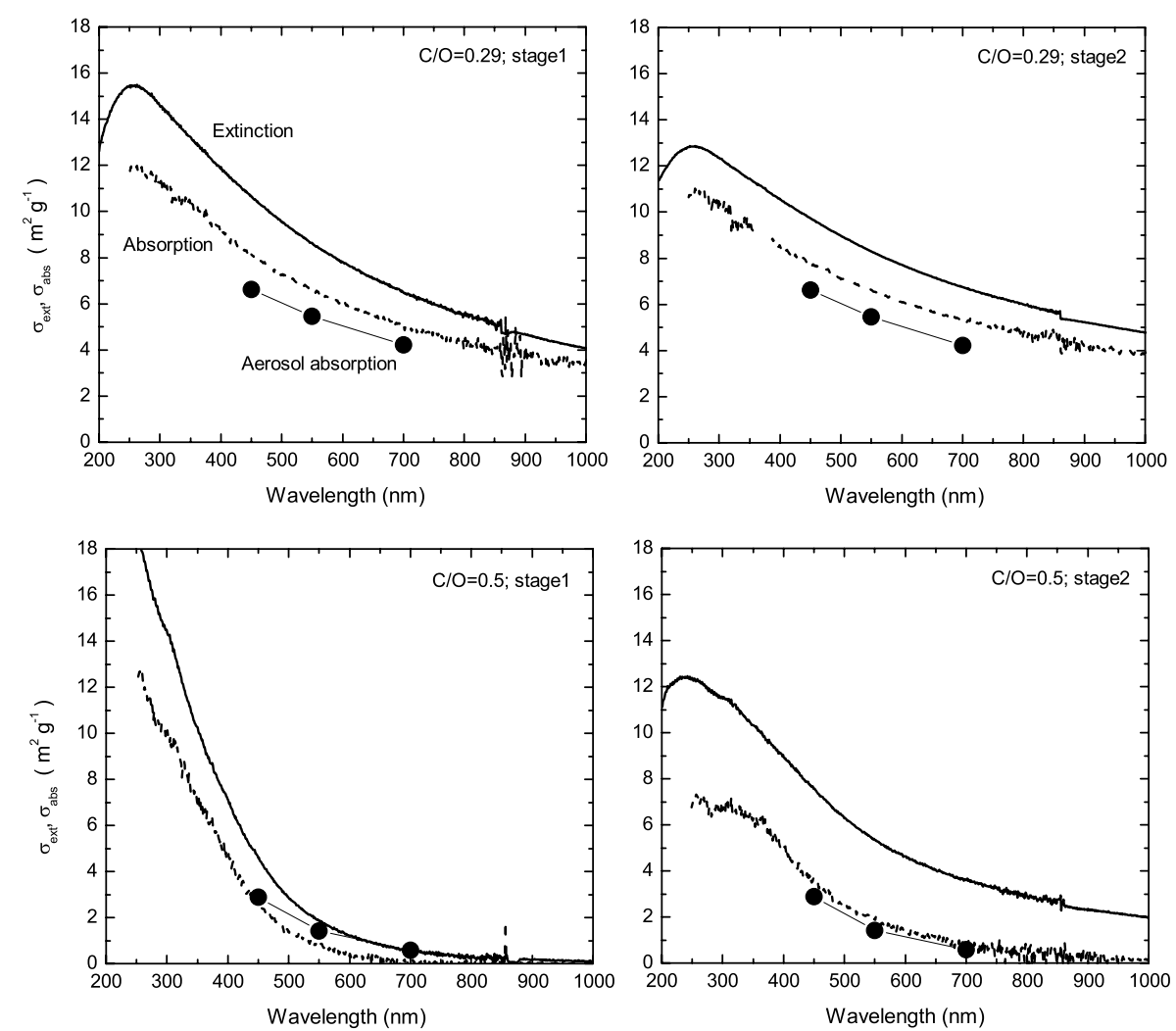

Fig. 7. Specific extinction and absorption cross sections for the deposited samples produced at C/O ratios of 0.29 and 0.50 . The absorption spectra (dotted lines) were measured with the Perkin-Elmer UV-VIS spectrometer in combination with the integrating sphere, as described in Sect. 4.1. The left panels show the data corresponding to the impactor stage 1 and the right panels show the data corresponding to the impactor stage 2 . The absorption values measured in the aerosol are included for comparison.

\subsection{Results}

The mass-normalized absorption and scattering cross sections are calculated from the extinction cross section, weighted with $A /(A+S)$ and $S /(A+S)$, respectively. Unfortunately, it is not possible to derive $\sigma_{\mathrm{abs}}$ from the absorption measurement alone, since absorption and scattering are competing processes and influence each other. The extinction and absorption cross sections obtained for samples produced at two distinct $\mathrm{C} / \mathrm{O}$ ratios $(0.29$ and 0.50$)$ are shown in Fig. 7 , with the left panels showing the data for impactor stage 1 , the right panels for impactor stage 2. For comparison, the $\sigma_{\text {abs }}(\lambda)$ values measured for the corresponding aerosols are also shown. The figure demonstrates that size segregation has a strong influence on the optical properties in case of the material produced at high $\mathrm{C} / \mathrm{O}$ ratio but not for the one produced at low $\mathrm{C} / \mathrm{O}$.

This becomes even more clear by comparing the optical quantities given in Table 2. The sample produced at $\mathrm{C} / \mathrm{O}=0.5$ has a lower absorption cross section and a higher absorption Ångström exponent $\alpha_{\mathrm{abs}}$ (both by factors of 2) when deposited at stage 1 compared to stage 2 . In comparison to the chamber measurements for aerosols produced at the same
$\mathrm{C} / \mathrm{O}$ ratio (compare Tables 1 and 2), the samples deposited at stage 2 have quite similar properties. In contrast to that, the sample deposited at stage 1 at $\mathrm{C} / \mathrm{O}=0.5$ appears to have again a lower absorption (by 43\%) and a much higher $\alpha_{\mathrm{abs}}$, which is in fact comparable to the one of the chamber aerosol produced at $\mathrm{C} / \mathrm{O}=0.61$. The single scattering albedo $\omega_{0}$ of the impactor-deposited samples is systematically lower than the corresponding $\omega_{0}$ values of the aerosol measurements, especially at shorter wavelengths. This may partially be a consequence of the shortcomings of the scattering measurement.

These results indicate that the size-separation by the impactor also leads to a separation according to the absorption properties. According to Fig. 2, the smallest size fraction (stage 1), should contain all compact particles of the size distribution up to a diameter of about $35 \mathrm{~nm}$ and may contain a minor fraction of small fractal aggregates up to a mobility equivalent diameter of $80 \mathrm{~nm}$. For the soot aggregates, the representation of the aerodynamic diameter ranges for the two impactor stages in terms of mobility equivalent diameters was performed by the COSIMA fractal formalism developed by Naumann (2003). Thus, stage 1 definitely contains the major part of the nucleation mode I of the particle size distribution discussed in Sect. 2, a small fraction of the 


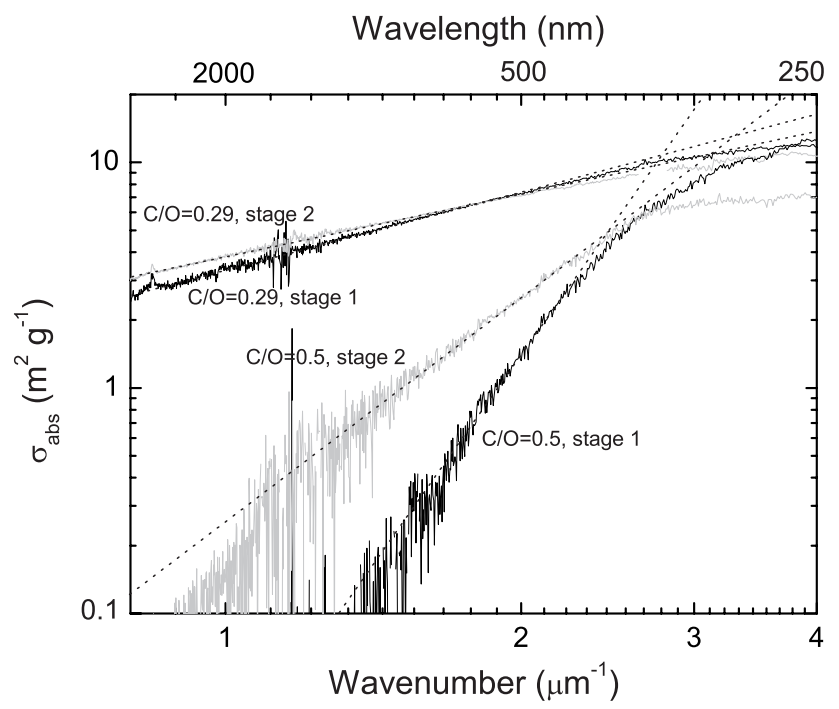

Fig. 8. Double logarithmic representation of the absorption behaviour in the visible range for samples produced at $\mathrm{C} / \mathrm{O}$ ratios of 0.29 and 0.50 and deposited on impactor stages 1 and 2 . The figure shows that the power-law behavior is no longer valid at wavenumbers larger than $2.5 \mu \mathrm{m}^{-1}$.

nucleation mode II, and only very few small soot aggregates. In summary, the aerosol fraction deposited on stage 1 is characterized by a low absorption at visible wavelengths, which however is steeply rising towards shorter wavelengths following a power law with a high exponent. Figure 8 indeed clearly demonstrates that the spectral dependence of the samples in the wavenumber range from about 1.3 to $2.5 \mu \mathrm{m}^{-1}$ can be well described by power laws. However, Fig. 8 also shows that the spectral absorption behaviour flattens considerably at shorter wavelengths (larger wavenumbers). Especially, for the OC dominated deposit it approaches a similar slope as that of the soot dominated deposit.

An interpretation of this behaviour can be given based on Fig. 9, which shows the extinction cross section extending to wavelengths as short as $167 \mathrm{~nm}$, plotted again on a wavenumber (energy) scale. Thus, the observed spectral dependencies are believed to represent different sections of similar absorption bands extending into the far UV spectral range. These bands are related to the excitation of the $\pi$-electron systems in aromatic structures (Apicella et al., 2004). The fact that not only the soot material produced at $\mathrm{C} / \mathrm{O}=0.29$ but also the organic carbon fraction deposited at $\mathrm{C} / \mathrm{O}=0.50$ possess this band, supports our assumption that a significant fraction of the nucleation modes observed in the CAST aerosol emissions consists mainly of condensed polycyclic aromatic hydrocarbons. However, for the $\mathrm{C} / \mathrm{O}=0.5$ sample deposited on stage 1 , this band is obviously sharper and peaks at longer wavenumbers. According to Robertson (2002), the decline of this band towards lower energies is related to the size of the aromatic regions within a carbonaceous material, with larger
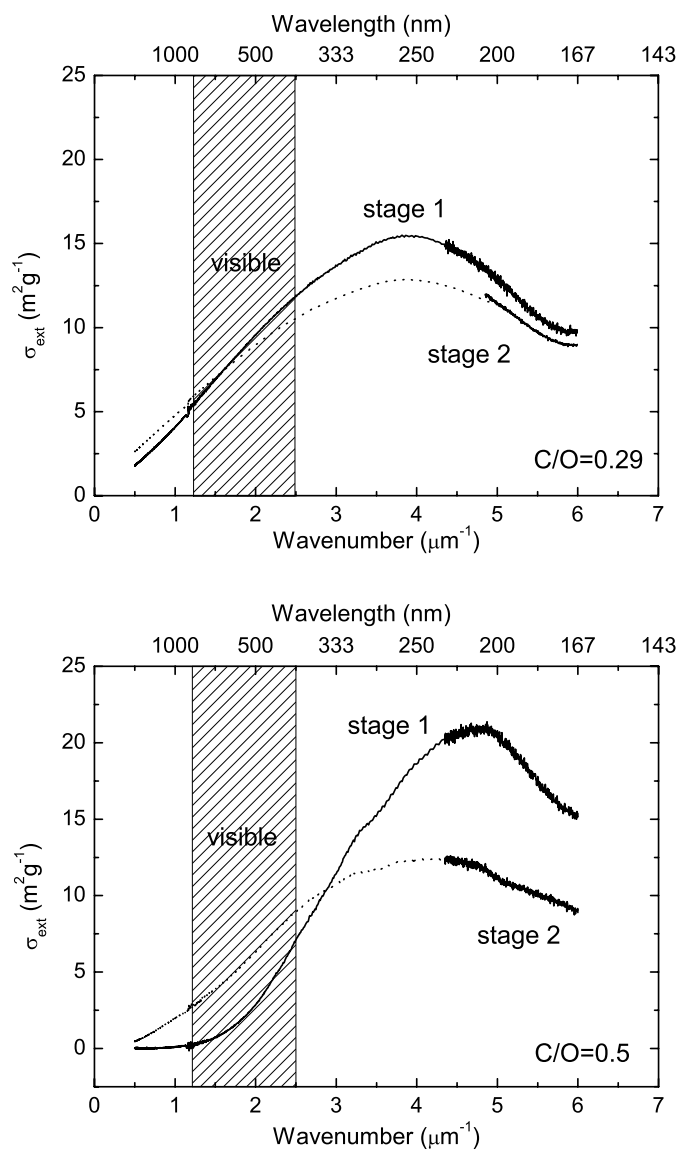

Fig. 9. Specific extinction cross sections corresponding to the samples produced with $\mathrm{C} / \mathrm{O}$ ratios of 0.29 and 0.50 and deposited at the impactor stages 1 and 2. The smooth (noisy) traces represent measurements with the UV-VIS spectrometer (the VUV spectrometer). The combined spectra reveal the presence of a prominent band with a maximum in the $3-5 \mu \mathrm{m}^{-1}$ range. The visual range where the Ångström exponent was determined is shaded.

aromatic regions leading to a decline at smaller wavenumbers (longer wavelengths), such as observed in the case of the CAST material produced at $\mathrm{C} / \mathrm{O}=0.29$. Consequently, in case of the soot material generated at a $\mathrm{C} / \mathrm{O}$ ratio of 0.29 the visible spectral range corresponds to a region directly within the long-wavelength side of the band. This spectral range with bulk absorption coefficients in excess of $10^{4} \mathrm{~cm}^{-1}$, depending on the mass density (extinction cross section values larger than about $1 \mathrm{~m}^{2} \mathrm{~g}^{-1}$ ) is usually described by the Tauc law (Robertson, 2002) giving a roughly linear ${ }^{1}$ spec- $^{-}$ tral dependence. This is reflected by the measured Ångström exponent of the soot material. For the organic carbon component, however, the visible spectral range extends into the very tail of the $\pi$-electron band (Urbach tail), where localized states contribute to the absorption mechanism. This transition in the absorption mechanism, together with some

\footnotetext{
${ }^{1}$ It is exactly linear for zero gap energy.
} 
residual contribution from small soot aggregates deposited on stage 1, could be responsible for the large Ångström exponent measured here.

\section{Conclusions}

The investigations carried out on airborne and deposited aerosol samples from a propane diffusion flame show that their extinction and absorption properties strongly depend on the $\mathrm{C} / \mathrm{O}$ ratio in the burner. It was found that at higher $\mathrm{C} / \mathrm{O}$ ratios nucleation modes of OC material, presumably of large PAHs, appear in the size distribution of the aerosol, in addition to the soot mode dominating at lower $\mathrm{C} / \mathrm{O}$ ratios. The appearance of these modes coincides with a strong decrease of the absorption cross section of the emitted aerosol accompanied by a strong increase of the absorption Ångström exponent. Size-selected measurements on deposited samples also indicate that the nucleation modes are related to the $\mathrm{OC}$ component of the CAST products, i.e. they most likely consist of condensable organic species characterized by low absoption and a high Ångström exponent in the visible range. Extension of the measurements into the VUV spectral range demonstrates that these optical properties of the OC originate from a $\pi$-electron absorption band in the UV, which is narrower and blue-shifted compared to the one of the sootdominated material. This indicates that the OC is mainly aromatic in nature, consisting probably of condensed polyaromatic molecules.

Acknowledgements. This work has been supported by the Helmholtz-Gemeinschaft Deutscher Forschungszentren as part of the program "Atmosphere and Climate" and by the Deutsche Forschungsgemeinschaft (grant Mu 1164/4). Further, it is part of a joint effort in Laboratory Astrophysics of the Friedrich-SchillerUniversität Jena and the Max-Planck-Institut für Astronomie, Heidelberg. We thank E. Kranz for the thermographic carbon analysis.

Edited by: R. Volkamer

\section{References}

Apicella, B., Alfe, M., Barbella, R., Tregrossi, A., and Ciajolo, A.: Aromatic structures of carbonaceous materials and soot inferred by spectroscopic analysis, Carbon, 42, 1583-1589, 2004.

Bond, T. C.: Spectral dependence of visible light absorption by carbonaceous particles emitted from coal combustion, Geophys. Res. Lett., 28, 4075-4078, 2001.

Bond, T. C. and Bergstrom, R.: Light absorption by carbonaceous particles: an investigative review, Aerosol Sci. Technol., 39, 141, 2006.
Bond, T. C., Anderson, T. L., and Campbell, D.: Calibration and intercomparison of filter-based measurements of visible light absorption by aerosols, Aerosol Sci. Technol., 30, 582-600, 1999.

Bond, T. C., Streets, D. G., Yarber, K. F., Nelson, S. M., Woo, J. H., and Klimont, Z.: A technology-based global inventory of black and organic carbon emissions from combustion, J. Geophys. Res.-Atmos., 109, D14203, doi:10.1029/2003JD003697, 2004.

Dobbins, R. A., Fletcher, R. A., and Chang, H. C.: The evolution of soot precursor particles in a diffusion flame, Combust Flame, 115, 285-298, 1998.

Fletcher, R. A., Dobbins, R. A., and Chang, H. C.: Mass spectrometry of particles formed in a deuterated ethene diffusion flame, Anal. Chem., 70, 2745-2749, 1998.

Homann, K. H.: Fullerenes and soot formation - New pathways to large particles in flames, Angew. Chem. Int. Edit., 37, 24352451, 1998.

Kirchstetter, T. W., Novakov, T., and Hobbs, P. V.: Evidence that the spectral dependence of light absorption by aerosols is affected by organic carbon, J. Geophys. Res.-Atmos., 109, D21208, doi:10.1029/2004JD04999, 2004.

Naumann, K.-H.: COSIMA - a computer program simulating the dynamics of fractal aerosols, J. Aerosol Sci., 34, 1371-1397, 2003.

Robertson, J.: Diamond-like amorphous carbon, Mat. Sci. Eng. R., 37, 129-281, 2002.

Schnaiter, M., Horvath, H., Möhler, O., Naumann, K. H., Saathoff, H., and Schöck, O. W.: UV-VIS-NIR spectral optical properties of soot and soot-containing aerosols, J. Aerosol Sci., 34, 14211444, 2003.

Schnaiter, M., Schmid, O., Petzold, A., Fritzsche, L., Klein, K. F., Andreae, M. O., Helas, G., Thielmann, A., Gimmler, M., Möhler, O. M., Linke, C., and Schurath, U.: Measurement of wavelengthresolved light absorption by aerosols utilizing a UV-VIS extinction cell, Aerosol Sci. Technol., 39, 249-260, 2005.

Slowik, J., Stainken, K., Davidovits, P., Williams, L., Jayne, J., Kolb, C., Worsnop, D., Rudich, Y., DeCarlo, P., and Jimenez, J.: Particle Morphology and Density Characterization by Combined Mobility and Aerodynamic Diameter Measurements. Part 2: Application to Combustion-Generated Soot Aerosols as a Function of Fuel Equivalence Ratio, Aerosol Sci. Technol., 38, 12061222, 2004.

Ulrich, E., Beckmann, C., and Israël, G.: The Characterization of Carbon Species in Particulate Matter by Successive ThermalDesorption, J. Aerosol Sci., 21, S609-S612, 1990.

Vander Wal, R. L.: Soot precursor carbonization: Visualization using LIF and LII and comparison using bright and dark field TEM, Combust Flame, 112, 607-616, 1998.

VDI: Measurement of soot (Ambient Air) - Thermographical determination of elemental carbon after thermal desorption of organic carbon, VDI 2465/2, in VDI/DIN manual Air Pollution Prevention Volume 4: Analysis and Measurement Methods, Beuth, Berlin, Germany, 1999.

Weingartner, E., Saathoff, H., Schnaiter, M., Streit, N., Bitnar, B., and Baltensperger, U.: Absorption of light by soot particles: determination of the absorption coefficient by means of aethalometers, J. Aerosol Sci., 34, 1445-1463, 2003. 